\title{
Campo intelectual y torre de marfil: acerca de cuatro cuentos de Enrique Serna
}

\author{
Elba Sánchez Rolón \\ Universidad de Guanajuato (México) \\ emsrolon@gmail.com
}

\begin{abstract}
Resumen: En la literatura mexicana reciente, la voz narrativa de Enrique Serna destaca por su marcado carácter crítico hacia las estrategias de poder presentes en el campo cultural. La ironía y formulaciones cercanas al absurdo dan forma a un malestar cultural presente en cuentos, novelas y ensayos. En este trabajo se revisan cuatro cuentos de este autor: "Hombre con minotauro en el pecho", "Borges y el ultraísmo", "Tesoro viviente" y "La fuga de Tadeo", desde la puntualización de algunos recursos narrativos que permiten mostrar diversas facetas de esta elaboración crítica donde se exponen mecanismos de legitimación, conservación y consagración dentro del campo intelectual.
\end{abstract}

Abstract: In the recent Mexican literature, the narrative voice by Enrique Serna stands out for its marked critical nature toward strategies of power present in the cultural field. The irony and formulations close to the absurd shape a cultural discomfort present in stories, novels and essays. In this work we reviewed four stories by this author: "Hombre con minotauro en el pecho", "Borges y el ultraísmo", "Tesoro viviente" and "La fuga de Tadeo", from the point of some narrative resources that allow you to display the various facets of this critical development where there are exposed mechanisms of legitimation, conservation and consecration within the intellectual field.

Palabras Clave: Realismo, ironía, crítica, legitimación, campo intelectual. KEYwORDs: Realism, irony, critique, legitimation, intellectual field.

El hombre es un animal que se alimenta de adulaciones.

William HazlitT

Psafón, joven pastor lidio, enseñó a los pájaros a repetir: "Psafón es un dios." Al oír que los pájaros hablaban y lo que decían, los conciudadanos de Psafón lo aclamaron como a un dios.

Pierre Bourdieu 


\section{REALISMO IRÓNICO Y MALESTAR CULTURAL}

En nuestro actual entorno literario, Enrique Serna (ciudad de México, 1959) se destaca por ficcionalizar y ensayar en un sector de su escritura un cuestionamiento a muchas de nuestras prácticas culturales, fundamentalmente desde una puesta en evidencia - muchas veces satíricade simulaciones y estrategias de poder presentes en el campo cultural, particularmente en el campo intelectual. ${ }^{1}$ La literatura de Serna da cuenta de un malestar, un descontento que alimenta el humor y la ironía de sus textos. En la base, se localiza una visión crítica de lo real, en busca de recursos para exigir al lector una reflexión sobre su entorno cultural.

Víctor Bravo sostiene que la ironía contemporánea es una forma de ver la realidad, y entendida desde su negatividad crítica no es solamente un uso retórico o una actitud subjetiva del autor, es fundamentalmente o por correspondencia: "un estado de mundo" (89). Este mismo autor añade que dentro de la conciencia crítica característica de la modernidad, la obra literaria recurre a la dualidad propia de lo irónico desde diversas posibilidades estéticas, entre ellas, la paradoja, el absurdo, la parodia y lo grotesco (93). Por su parte, Serna ha señalado que para acercarse a describir la realidad actual de México, las estéticas de lo grotesco y de lo absurdo son necesarias. En una entrevista con La Jornada Semanal en 1992 apunta: "la imagen de una época tan dura como la que se vive en México a partir de los ochenta, requiere de un manejo de lo grotesco para acercarse a la descripción de la realidad” (en Hernández, 1992: 24); e insiste en esta idea en entrevistas posteriores: "siento que el realismo en la literatura mexicana actual colinda forzosamente con la estética del absurdo" (citado por Martínez: 251-252).

Si se rescata de estas afirmaciones, en primer término, la pretensión crítica realista como fundamento de su propuesta literaria, algunos de los cambios en su entorno cultural cobran relevancia para contextualizar su interés por la ironización de la realidad dentro de la heterogeneidad de su obra. Cabe recordar que su primera novela, El ocaso de la

${ }^{1}$ Pierre Bourdieu describe el funcionamiento del campo intelectual como un "sistema de líneas de fuerza" donde todos los agentes que participan de la creación intelectual se encuentran en interacción y asumen en él posiciones y estrategias para obtener dichas posiciones. El poder de cada agente en el campo intelectual dependerá de la posición que ocupa en él y del sistema de fuerzas al que pertenece (cfr. 2003: 241-242). 
primera dama, se publica en Campeche en 1987 y se reedita después como Señorita México en 1991. Inicia así su "carrera" literaria en años cercanos a la conformación del Consejo Nacional para la Cultura y las Artes y posteriormente a la creación del Fondo Nacional para la Cultura y las Artes en 1989; así como al inicio del impulso a otros programas destinados en primera instancia a otorgar apoyos y premios al mundo intelectual y literario. Por supuesto, un impulso elogiable en muchos sentidos, pero no exento al juego del poder en su interior, al arrancar un proyecto de descentralización que al mismo tiempo participa de la institucionalización del poder cultural mediante el fortalecimiento de sus mecanismos de concentración grupal (cfr. José Agustín: 215). Este impulso, sumado a la reorganización de los espacios ocupados por el campo intelectual de la época pondrán una vez más sobre la mesa la reflexión en México acerca del estrecho vínculo entre el poder y la clase letrada, con las consabidas implicaciones en procesos de legitimación y canonización. Mayor peso adquiere esta reflexión ante el Premio Nobel otorgado a Octavio Paz en 1990 y todas las polémicas que durante el siglo pasado suscitó su figura en este mismo sentido.

A su vez, destaca en este panorama el empoderamiento de los medios masivos de comunicación - particularmente la televisión- que venía gestándose desde las décadas anteriores, y propicia un "intercambio" de estrategias de legitimación con el campo intelectual, así como un cruce de discursos. Al respecto, la cercanía entre mundo letrado y farándula es rescatada por Serna en sus obras literarias, como parte de un contacto real y una permeabilidad discursiva, presente no solo en $\mathrm{El}$ ocaso de la primera dama o Señorita México, sino también en su segunda novela: Uno soñaba que era rey (1989). En su caso, nada raro, ya que, como él mismo señala, esta característica está enlazada con su formación: "Como el trabajo lo alterné con mis estudios de letras, siempre he estado metido en dos ambientes: el académico y el de la farándula”; y añade que en sus textos y en su entorno existe "un acercamiento entre la cultura de masas y la alta cultura. Ya no hay una división tajante, sino que se ha llegado a un estado intermedio" (en Torres: 403).

Su crítica a las ambiciones, vicios y apariencias del campo cultural está presente en toda su narrativa, pero toma formas diversas que van desde la sátira de la cultura de masas en sus dos primeras novelas, hasta su novelística histórica: El seductor de la patria (1999) y Ángeles del abismo (2004). Por otra parte, la ironía y el género satírico funcionan como 
estrategias constantes para enfatizar una crítica abierta y nunca condescendiente tanto en sus textos de corte histórico, como en aquellos enfocados en otros ámbitos de la reflexión de la cultura. ${ }^{2}$ En este marco, la crítica al campo intelectual y sus protagonistas se encuentra reflejada directamente en una novela de género negro: El miedo a los animales de 1995; así como en varios de los cuentos incluidos en dos libros: Amores de segunda mano, publicado por la Universidad Veracruzana en 1991 y reeditado con tres relatos adicionales en Cal y Arena en 1994, y El orgasmógrafo de $2001 .^{3}$

En el caso de sus cuentos, si bien algunos han sido reconocidos ampliamente por la crítica, los relatos incluidos en estos dos primeros libros —en 2013 publica un tercer libro de cuentos, La ternura caníbal - resaltan por su diversidad temática y porque algunos logran una reconocible dimensión satírica no uniforme en todo el conjunto. Para las siguientes líneas he seleccionado aquellos cuentos que se enfocan directamente a la crítica del campo literario o del artístico: dos textos de Amores de segunda mano, "Hombre con minotauro en el pecho" y "Borges y el ultraísmo"; y dos textos de El orgasmógrafo, "Tesoro viviente" y "La fuga de Tadeo". Estos cuatro relatos presentan características críticas en común que permiten leerlos, así lo propongo, de forma complementaria. Al mismo tiempo, podría incluirse en la lista de escrituras satíricas de la vida intelectual la novela Elmiedo a los animales, que no es objeto de este trabajo, y varios de sus ensayos publicados en Sábado y Letras Libres. ${ }^{4}$

Como ha destacado Leonardo Tarifeño, "su obra nace de un malestar con el mundo que se estetiza para revelarse, y en ningún caso para ocultarse o refinarse" (75). Este malestar, aunado al afán realista localizable en su trabajo produce una búsqueda de elementos para acercar al lector con diversas facetas de la simulación persistentes en los cam-

2 La sátira se entiende en este contexto desde el enfoque recuperado por Linda Hutcheon: "forma literaria que tiene como finalidad corregir, ridiculizándolos, algunos de los vicios e ineptitudes del comportamiento humano. Las ineptitudes a las que de este modo se apunta están generalmente consideradas como extratextuales en el sentido en que son, casi siempre, morales o sociales y no literarias" (178). Para esta autora la diferencia entre sátira y parodia radica precisamente en el carácter extratextual de la sátira, frente al carácter intertextual de la parodia.

3 Para este trabajo se citan las ediciones de 1994 de Amores de segunda mano y la primera edición en Debolsillo de El orgasmógrafo, de 2004.

${ }^{4}$ Los libros Las caricaturas me hacen llorar (1996) y Giros negros (2008) compilan algunos de estos ensayos. 
pos literario y artístico en el caso de los cuentos aquí revisados. A este respecto, ha señalado Ignacio Solares que el arte de Serna "consiste en una serie de procedimientos encaminados a hacernos más persuasiva la ilusión realista [...], a comunicar al lector la sensación de estar siendo directamente enfrentado a la vida" (92). Este efecto es logrado a partir de una puesta en escena de las situaciones narradas, donde quedan en primer plano los juicios de sus participantes y se propone una distancia de cualquier voz autoral o narrativa que pueda tener privilegios interpretativos sobre el universo narrado. De esta forma, el lector se enfrenta a los relatos equipado con su propia experiencia y prejuicios sobre el campo cultural. Puede adelantarse que la ironía presente en ellos adquiere una dimensión pragmática que atraviesa el discurso y adquiere valor contextual, más allá de su función semántica (cfr. Hutcheon: 174-176). De esta forma, el texto exigirá al lector poner las diversas situaciones narrativas en perspectiva y replantearlas en función de un cuestionamiento a la honestidad de nuestra propia participación en estos juegos de poder y reconocimiento.

Desde el punto de vista de Serna, este afán realista es también confrontador, y apunta: "como vivo en un país avergonzado de su realidad, cualquier acercamiento a ella está mal visto por el establishment cultural que en este caso imita las élites económicas" (citado por Martínez: 251-252). El juego es doble y conduce a la paradoja: los textos de Serna apuestan por la neutralización de una voz que tome partido o elabore un juicio explícito de sus personajes y su comportamiento; sin embargo, la misma codificación textual exige al lector esta posibilidad interpretativa, sin la cual pierden sentido los relatos. Serna ha afirmado sobre este aspecto: "No me siento juez de la sociedad, como para repartir penas y absoluciones" (en Jeannet: 153); y reitera que su pretensión es únicamente realista. Con todo, es importante subrayar que se trata de un realismo irónico, es decir, una exposición de las situaciones y los juicios donde impera la exigencia a una doble lectura, principalmente, la puesta en duda de la validez y motivación de los puntos de vista de los diversos enunciadores, mediante su confrontación con las perspectivas de la trama y del lector. Como ha destacado Linda Hutcheon, "la función pragmática de la ironía consiste en un señalamiento evaluativo, casi siempre peyorativo" (176).

Los cuatro cuentos que voy a comentar se arman de este procedimiento para su elaboración crítica. En ellos, la pluma de Serna no se 
detiene ante el cuestionamiento mismo del valor del objeto artístico - la literatura incluida - y los absurdos derroteros de autores y críticos para participar de diversas estrategias de legitimación, conservación y pretendida consagración dentro del campo intelectual.

\section{LA EXALTACIÓN CRÍTICA Y EL RECONOCIMIENTO PÚBLICO}

Incluido desde la edición de 1991 de Amores de segunda mano, el cuento "Hombre con minotauro en el pecho" aparece, por lo menos, en un par de conocidas antologías sobre narrativa mexicana. ${ }^{5}$ A decir de Christopher Domínguez Michael, lo que llama su "altísimo valor antológico" (1647), radica, entre otras cosas, en su "ambición por revisar el realismo de consecuencias inéditas" y construir lo que el crítico considera una propuesta hiperrealista (1461). Más allá de este reconocimiento — valor que los mismos cuentos tratados ponen en entredicho-, es destacable en este texto la utilización de una voz narrativa en la primera persona del protagonista que permite acompañarlo en una exposición autobiográfica ficcional de su despersonalización a raíz de haber sido tatuado en el pecho por Picasso con un minotauro. La temática es por sí misma ya muy sugerente.

En el cuento, el protagonista es sometido a los abusos de la mercantilización del objeto artístico y de una distorsionada crítica de arte que buscan en él diversas explicaciones o justificaciones a su propia razón de ser a través de mecanismos legitimadores, enmarcados en el entorno posvanguardista europeo. La innovación y originalidad de la "pieza" - el cuerpo mismo del protagonista - son resaltadas por los supuestos críticos. El hombre-minotauro es vendido al mejor postor (coleccionistas, museos, gobierno) y hasta robado por unos esnobs destructores del arte. La deshumanización del protagonista llega al grado de que él mismo se convierte en su promotor. La situación vivida lo envuelve de tal forma que busca sacar provecho personal y se prostituye con "una clientela de millonarias excéntricas que pagaban sumas exorbitantes por irse a la cama con una obra maestra del arte contemporáneo" (Serna 1994: 63). La narración sigue hasta que el protagonista se da

5 Me refiero a las antologías: Domínguez Michael 1996: 1647-1663 y Cluff et al. 2000: 785-805. 
cuenta de que no puede ya vivir sin la adulación. De esta forma, narra cómo la posibilidad de tener una vida relativamente "normal" como estudiante universitario ya no es suficiente para él ante su irrefrenable deseo exhibicionista (65). El estilo utilizado colinda con el absurdo y su rebasamiento de cercos racionales, a favor de situar en el límite de toda lógica la narración literaria; con el cuidado de no llegar al extremo de la pérdida de sentido o posibilidad comunicativa.

El recorrido constituye una revisión de la vida del protagonista desde la cárcel. Ahí permanece preso por haber destruido su tatuaje, es decir, por la destrucción de una obra de arte considerada "un bien nacional" (66). Así, el odio que profesa a Picasso, visto como su creador y no solo como autor del tatuaje (57), se enlaza con el inicio del texto donde explica las razones para contar su vida:

Todos festejan el incidente, creyendo que Picasso dio una lección a los mercaderes del arte. [...] Sé que mienten. Lo sé porque yo era el niño del tatuaje y mi vida es una prueba irrefutable de que la rapiña comercial triunfó sobre Picasso (49-50).

¿Cuál es, entonces, el valor del objeto artístico? En el texto parece proponerse que esta atribución social de un valor al arte responde más a intereses de reconocimiento público que a algún mérito de la obra. La firma de Picasso es el principal elemento de valoración mercantil. Los consumidores e instituciones (críticos, museos y gobierno) la utilizan para alcanzar un cierto estatus en el campo cultural. Sirva como ejemplo la primera poseedora del hombre-minotauro, la señora Reeves, quien ingresa a una élite intelectual gracias a su nueva adquisición: "obtuvo con la cena un gran éxito social. Fue algo así como su doctorado en sofisticación, la prueba de refinamiento que necesitaba para entrar al gran mundo" (52). La imagen grotesca de este personaje está reforzada por todas sus descripciones como una millonaria ociosa y con ambiciones de gran conocedora, que como sus amistades apenas atinaba a decir it's gorgeous ante su socialmente remunerativa obra de arte (53).

Serna se sirve en este caso de la configuración de un realismo grotes$c o$, con toda la exageración y desfiguración material desde un entorno festivo y lúdico de tradición cómica popular, como lo describe Mijaíl Bajtín en su famoso estudio sobre Rabelais (cfr. 1998: 47). La diferencia en este caso, producto también de la distancia histórica, radica en la 
potencialización de ese cruce interdiscursivo — una forma de bilingüismo- de la cultura de masas y sus artificios de legitimación mercantil con el arte; además, en la configuración del cuerpo grotesco del protagonista no solo desde la excrecencia, sino a partir de la introducción/ equiparación de su cuerpo con un objeto artístico. En este sentido, la sátira — con su carga de juicio a las actitudes y al comportamientohace uso del grotesco — sin eludir esa materialidad deformada, como el cuerpo obeso, de una "elefanta", de la señora Reeves (Serna 1994: 51) y la descripción de las orgías de Uninge (61-62) — para salir del texto y exigir al lector una respuesta.

Además, vale la pena señalar que la participación de todos estos consumidores del arte no llega a la actualización o apropiación de un repertorio, según lo describe Itamar Even-Zohar: "conjunto de reglas y materiales que regulan tanto la construcción como el manejo de un determinado producto, o en otras palabras, su producción y su consumo" (1999b: 31). Esto se debe a que no hay ninguna interacción real. Ensimismados en su esnobismo, no acceden siquiera a la obra y su dinámica social como parte del repertorio, precisamente por su "falta de conocimiento o competencia" (33). Otro caso, aunque muy semejante a los anteriores, es el del profesor universitario que trata de utilizar al protagonista para demostrar en su tesis doctoral "la vigencia del ciclo mercancía-dinero-mercancía en la economía política de la producción artística" (Serna 1994: 64). Su objetivo, a fin de cuentas, es también la legitimación de su propio trabajo, vinculado con su posición y pertenencia a la institución académica.

El juego de las apariencias y la obtención de un estatus no son privativos de los consumidores del arte en este texto: coleccionistas, guías de museo o críticos improvisados. El cuento "Borges y el ultraísmo", también del libro Amores de segunda mano (1991), ubicará la discusión directamente en los territorios de la academia y los autores consagrados del boom latinoamericano.

El texto configura dualidades complementarias entre protagonistas y tematizaciones. La primera dualidad corresponde al antagonismo entre Florencio Durán, el gran escritor perteneciente a este "Parnaso latinoamericano", y Silvio, un investigador de literatura y docente de una universidad situada en los Estados Unidos. La confrontación surge desde las primeras líneas de la narración, cuando Florencio cuestiona en un evento público en su honor, el tema de tesis doctoral de Silvio: 
Lo dijo con la deferente gentileza de un patriarca interesado en la juventud estudiosa, pero haciéndome sentir el rigor de su augusta, indiscutible autoridad literaria. Y lo dijo en voz alta, para que oyeran el consejo todos los profesores del departamento (Serna 1994: 101).

La voz autorizada y considerada jerárquicamente superior de Florencio deja en silencio a todos los presentes. Esta exaltación a la figura del autor consagrado refiere a una posición otorgada culturalmente que, por supuesto, remite a un horizonte histórico donde su individualidad adquiere un valor que en ocasiones rebasa a su obra. Michel Foucault, en sus conocidas reflexiones sobre el autor, lo describe como una función "característica del modo de existencia, de circulación y de funcionamiento de ciertos discursos en el interior de una sociedad" (338); función enmarcada por el campo cultural al que pertenece. Asimismo, Foucault ańade: "Estamos acostumbrados a pensar que el autor es tan diferente a todos los demás hombres, hasta tal punto trascendente a todos los lenguajes, que a partir del momento en el que habla el sentido prolifera y prolifera indefinidamente" (350).

En el cuento de Serna, el consejo de Florencio respecto a la tesis de Silvio adquiere esta jerarquización superior: su valor de verdad ante los otros radica en la posición que juega el escritor como instancia superior frente al académico dentro del universo narrativo. Sobre la malla de poder generada por este juego de posiciones, refiere Pierre Bourdieu:

en el seno del campo intelectual como sistema estructurado, todos los individuos y todos los grupos sociales que están específica o duraderamente abocados a la manipulación de los bienes de la cultura [...], sostienen no solo relaciones de competencia sino también relaciones de complementariedad funcional, de modo que cada uno de los agentes o de los sistemas de agentes que forman parte del campo intelectual debe una parte más o menos grande de sus características a la posición que ocupa en este sistema de posiciones y oposiciones (2003: 271).

La interpretación ficcional que Serna realiza en el cuento sobre las posiciones autor y académico en su horizonte cultural, remite a esta colocación del escritor como instancia privilegiada, legítima y reconocida por los otros. No obstante, esta reconstrucción está sustentada en el énfasis de su competencia con la instancia académica, más que en la complementariedad funcional latente. Aún así, el mismo Silvio parece 
reconocer también esta jerarquía, como puede leerse en las siguientes líneas:

Entre Durán y yo había una distancia infranqueable. Por simple respeto a las jerarquías debía guardar silencio, como un soldado raso obedece instrucciones de su general. ¿Quién era yo junto a él? Un oscuro especialista, un parásito del talento ajeno. Pero entonces ¿por qué se había ensañado conmigo? (Serna 1994: 102).

Silvio le reprocha a Florencio su falta de solidaridad como escritor con el gremio académico, pero lo hace desde el prejuicio operante de calificarse a sí mismo como "un parásito del talento ajeno". No obstante, esta descalificación inicial contrasta con una reafirmación posterior de su papel dentro del campo literario, posición basada en una institución legitimadora de sus productos y productores. Afirma Silvio un poco después: "Modestia aparte, soy el investigador más brillante de esta maldita universidad"; en una actitud de refugio en valores gremiales (102). Se cobija, por tanto, en la idea de institución como la instancia autorizada para "el control de la cultura", es decir, para determinar el valor de los bienes culturales y, por atribución, de sus productores (ver Even-Zohar 1999b: 49). De ahí que sea mucho más molesto para Silvio percatarse que esa "maldita universidad", esa institución a la que pertenece, cede ante los encantos del escritor consagrado.

El segundo golpe a su ego está vinculado con la actividad docente de Silvio y su papel activo en la conservación de un canon y una forma de entender la literatura, mediante el establecimiento o repetición de contenidos educativos obligatorios (ver Bourdieu 2003: 272). Lo que queda en cuestión es la autoridad de Silvio frente a sus alumnos:

Además de perjudicarme como investigador, me desacreditó como docente. La mayoría de mis alumnos tomaba clase con él (había venido a impartir un curso de tres meses pagado a precio de oro) y sus brutales embestidas contra la moderna ciencia literaria empezaron a crearles dudas. Después de oírlo venían a decirme que los métodos de análisis estructural eran grilletes para la imaginación. [...] Predicaba en el desierto, pues ahora me habían perdido el respeto. Un escritor "de a de veras" les recomendaba tirar a la basura mis enseńanzas (Serna 1994: 106-107). 
La crítica no es, por supuesto, a un solo modelo teórico, sino a lo que representa dentro de la institución académica. ${ }^{6}$ Florencio tiene el atrevimiento de tocar, esta vez, el estatuto de validez de estos contenidos y, por tanto, poner en entredicho la posición de Silvio. Incluso, llega al grado de cambiarle de nombre: para él se llama "Eduardo" (118), en una abierta burla a su falta de posición en el campo literario donde él es toda una figura.

En cuanto a la dualidad temático-anecdótica, el texto relata tanto el enfrentamiento entre los protagonistas como la infidelidad de la esposa de Florencio Durán, Mercedes, precisamente con Silvio, el opacado académico. Por supuesto, Silvio es quien propicia esta infidelidad alentado por la afrenta que considera haber recibido del escritor. Es su manera de tratar de despojarlo de algo. Así, se esfuerza primero por hacer que Mercedes acceda a su cortejo y, posteriormente, porque Florencio se entere de la infidelidad.

En este doble juego anecdótico, plagado de analogías, en voz de Silvio vuelve a construirse un planteamiento irónico sobre los estudios académicos. Al tratar de seducir a Mercedes, compara lo estratégico de sus escarceos con sus habilidades como estudioso de la semiología (105). Por tanto, una semiología que en la perspectiva de la trama no sirve de mucho ante la autoridad del escritor frente a sus colegas y alumnos, pero que pretende tenga mayor efecto en la seducción de la mujer de su oponente. Al respecto, pueden retomarse aquí los siguientes señalamientos de Linda Hutcheon sobre la función pragmática de la ironía, en donde "la burla irónica se presenta generalmente bajo la forma de expresiones elogiosas que implican, al contrario, un juicio negativo" (176-177).

La construcción irónica está presente en todo el texto a partir de estas dualidades de sentido, sin embargo, el factor fundamental de ironización del relato se encuentra en sus últimas líneas. Después de haber seguido la narración desde la voz de Silvio con todas sus diatribas y quejas, el lector es informado que Florencio ha sido todo este tiempo el

${ }^{6}$ En varios de sus ensayos publicados en Letras Libres, Serna vuelve al cuestionamiento sobre el papel y comportamiento de la crítica académica. Al respecto, su principal malestar radica en la distancia que gran parte de su metalenguaje - "muletillas", les llama también — ha propiciado respecto a los lectores, al grado de negar el carácter comunicativo que le interesa resaltar en toda actividad vinculada con la literatura. Como ejemplos, pueden revisarse Serna 2000: 87 y 2002: 65. 
mediador de esta voz — una especie de autor implícito ficcional y con función vocal además de diegética- $\mathrm{y}$ ahora se manifiesta para descubrir que todo el texto constituye una focalización interna a su punto de vista de lo ocurrido. Ańado el fragmento, dada su relevancia para la interpretación del cuento. La voz inicial sigue siendo, por lo menos aparentemente, la de Silvio:

Pero nada sucedió como lo había planeado. Mercedes no fue descubierta y solo estaba furiosa por mi tardanza. Florencio ni siquiera se tomó la molestia de vigilarla. El mismo día que leyó el anónimo tomó sus maletas y se largó a París, donde se ha dedicado a escribir la narración que ahora estás leyendo como si de tu boca saliera. ¿`Verdad que parece escrita por ti? ¿Verdad que parece un autorretrato? Si no te reconoces en él será porque embellecí tu carácter. Mil disculpas: el esperpento psicológico es un género que no domino.

Confío en que ya te habrás librado de Mercedes cuando el relato llegue a tus manos. Gracias por quitármela de encima. Tampoco yo la soportaba desde que se le metió en la cabeza el gusanito del arte. Creo que me tenía envidia ¿sabes? Nunca te dejes arrastrar por ese pecado. Pero cómo se me ocurre decírtelo a ti, si me consta que tienes un corazón de oro. Debo terminar ya porque se me hace tarde para llegar a una cena en el Quai d'Orsay. Gorbachov aprecia mucho a los intelectuales, pero detesta la impuntualidad. Si supieras cuánto me aburren estos compromisos... Saludos a Murray y suerte con la tesis, Eduardo (Serna 1994: 130).

El giro drástico o revelación en la voz enunciativa, produce una resignificación irónica de todo el cuento, que refuerza su carácter satírico. El tono de Florencio y sus afirmaciones contribuyen a dar vuelta al cuadro y presentarnos en el conjunto del texto una crítica ya no solo a los vicios del académico ofendido, sino a la soberbia del escritor. Desde su propio punto de vista, Florencio se autopresenta como un triunfador: está más allá del mundo de las universidades y sus profesores, a quienes puede caricaturizar y de quienes no podría recibir agravio alguno. Después de la lectura de estas últimas líneas, la exaltación que parecía formular Silvio del escritor no es más que autoadulación y las aparentes autojustificaciones del académico no son más que la burla elaborada por el escritor, mediante el recurso de la ironía. Sin embargo, esto no diluye la crítica hacia la institución académica: ambos, institución y 
productor forman parte de este juego de máscaras e infidelidades del campo literario.

\section{LOS BALUARTES NACIONALES Y EL AUTISMO LITERARIO}

¿En qué consiste la consagración literaria? Dada la variabilidad y complejidad en la atribución de un valor a la obra de arte, es importante considerar, como señala Pierre Bourdieu, que:

El productor del valor de la obra de arte no es el artista sino el campo de producción como universo de creencia que produce el valor de la obra de arte como fetiche al producir la creencia en el poder creador del artista. Partiendo de que la obra de arte solo existe como objeto simbólico provisto de valor si es conocida y está reconocida, es decir si está socialmente instituida como obra de arte por unos espectadores dotados de la disposición y competencia estéticas necesarias para conocerla y reconocerla como tal (1995: 339; cursivas en el original).

La dimensión histórica, sociológica y cultural de esta atribución de valor ha sido destacada ya líneas más arriba. Interesa resaltar ahora que dicho reconocimiento conlleva el establecimiento de lo que puede llamarse un "capital simbólico", administrado por instituciones que por lo regular se imputan directamente este derecho o, por lo menos, siguen haciendo uso de él. La consagración literaria es, así, una forma de funcionamiento específica del capital simbólico, aquel puesto en juego por los actores del campo literario (cfr. Romero y Santoro: 208).

La posibilidad de que esta consagración y su reconocimiento se encuentren desvinculados de la obra en sí y se concentren en su productor ha sido también planteada en el caso de los cuentos comentados hasta ahora. Sin embargo, adquiere un tratamiento radical en el cuento "Tesoro viviente", incluido en el libro El orgasmógrafo (2001), donde se convierte en un mecanismo de poder útil a un régimen dictatorial; una vez más el absurdo está presente en la construcción del límite de la posibilidad realista.

Tekendogo es un país africano gobernado por el dictador Bakuku. Amélie, una aspirante francesa a escritora, es contratada por una agencia dedicada a difundir la literatura de autores africanos en el continen- 
te europeo. Su tarea es viajar a Tekendogo y escribir sobre la literatura actual de aquel país, con la advertencia de no intervenir en ninguna actividad política (Serna 2004: 32). Esto último no será tan sencillo, como es de esperarse.

Al llegar a Tekendogo, Amélie se entera de que en aquel país los escritores y artistas reciben el calificativo de "tesoros vivientes". En el Ministerio de Cultura le explican que se trata de un título honorífico decretado por el dictador, "el excelentísimo general Bakuku". Su función es proteger la literatura y las artes nacionales, otorgándoles a los artistas una generosa pensión a cambio de que entreguen sus obras al pueblo (39-40). La primera impresión de Amélie es, claro, positiva. Al salir del Ministerio reflexiona sobre la lección que representa Tekendogo frente a "los roñosos gobiernos de las grandes potencias, que recortaban sin piedad el presupuesto para las actividades culturales" y se alegra porque pueda existir una literatura libre de "la demencial tiranía del mercado" (40).

Sin haber conseguido todavía ningún libro de un tesoro viviente, asiste a una ceremonia pública con motivo de la presentación de la nueva novela de uno de ellos. El espectáculo se encuentra encabezado por el dictador en persona y el lugar, resguardado por la milicia. Esta configuración recuerda las líneas de Rama para definir su famosa propuesta sobre la ciudad letrada, en el libro del mismo nombre:

Para llevar adelante el sistema ordenado de la monarquía absoluta [dictadura en este caso], para facilitar la jerarquización y concentración del poder, para cumplir su misión civilizadora, resultó indispensable que las ciudades, que eran el asiento de la delegación de los poderes, dispusieran de un grupo social especializado, al cual encomendar esos cometidos. Fue también indispensable que este grupo estuviera imbuido de la conciencia de ejercer un alto ministerio que lo equiparaba a una clase sacerdotal. Si no el absoluto metafísico, le competía el subsidiario absoluto que ordenaba el universo de los signos (23).

Sin embargo, no es el elitismo o jerarquización superior de los artistas, sino la muestra patente del estrecho lazo entre el poder político y el campo literario lo que asquea a Amélie, quien expone una postura extremadamente estereotipada - claro, no exenta de idealismo, en el sentido más coloquial del término- de la exaltación de la autonomía 
del creador. Su interpretación es la que leemos a continuación: "el papel protagónico del dictador reflejaba su afán de legitimarse a costa de los artistas, de utilizar la cultura como una plataforma de lucimiento. [...] El supuesto esplendor literario de Tekendogo lo ayudaba a mantenerse en el poder tanto como los tanques o los cañones" (Serna 2004: 48).

La repugnancia de Amélie ante esta ceremonia y su anterior aprobación de las pensiones a los artistas a favor de una literatura libre del mercado van de la mano con una doble configuración crítica de la protagonista, soportada en la confrontación de perspectivas narrativas de lo narrado y de la protagonista, principio básico de la construcción irónica del texto. Por un lado, Amélie busca el reconocimiento de una obra que no cuenta con más de una línea hasta ahora. Cuestiona a sus amigos franceses por falta de disciplina, pero ella misma no logra escribir nada. En congruencia, al poco tiempo de llegar a Tekendogo ante las primeras dificultades se olvida de su tarea para enfocarse en su reciente relación con Sangoulé, su profesor de malinké, la lengua natal. Sus afirmaciones son siempre tajantes y corresponden a juicios de aprobación o desaprobación de las circunstancias. Se suma a ello una idea de literatura despojada de cualquier función social, incluso esa función comunicativa que Serna defiende rescatar en muchos de sus relatos y ensayos. Su aspiración en su escritura, como ella lo propone, es volver a esa "oscura raíz de lo inexpresable" que atribuye a Mallarmé. Una postulación del silencio y el vacío como fin último de la literatura. No es gratuito titular Alto vacío el libro que trata de escribir.

Así, en una parodia llevada al extremo del absurdo de esta escritura blanca o vacía, Amélie descubre finalmente que los tesoros vivientes no escriben, sus libros son "maquetas empastadas con las hojas en blanco" (55). Tekendogo es un país donde la dictadura se legitima a través de una ritualización del campo cultural desprovista de cualquier producto. Como señala Even-Zohar:

En casos muy extremos las personas que en potencia están capacitadas para producir textos son más importantes que los productos. No puedo dejar de pensar, por ejemplo, en Asuracenturix, este poeta de la aldea gala de Asterix, que nunca tiene permiso para cantar sus poemas, aunque su papel como "el poeta de la aldea" sea indispensable. En Galicia, como sin duda en otros lugares, todavía se conocen estos "poetas de aldea" cuyos únicos productos textuales son sus descripciones detalladas de cómo van a escribir sus poemas (1999a: 30). 
La explicación proporcionada por Luenda, subjefe del Ministerio de Relaciones Internacionales, concuerda con este planteamiento: "nuestros tesoros vivientes cumplen una función más importante que la de borronear cuartillas. Son baluartes de la identidad nacional" (Serna 2004: 56). En Tekendogo la consagración de los autores, así como los comentarios sobre sus obras no escritas, funcionan como mecanismo de poder útil al régimen, ya que le permiten reafirmar su posición y dar sentido al sentimiento de pertenencia a una "aldea" o "nación". En otros términos, constituyen el repertorio virtual que los define como grupo cultural, aun cuando nunca tengan acceso a ningún producto de él. Esta configuración constituye una puesta al límite del absurdo de la importancia que se otorga a la ciudad escrituraria, en términos de Ángel Rama (41), dentro de este grupo jerárquico denominado por él ciudad letrada, ya que el valor que se confiere a la escritura se encuentra soportado en el relato de Serna por la falsedad de su ejercicio. Lo relevante es que los poetas o baluartes nacionales de Tekendogo ponen en juego críticamente dos de las características fundamentales de la ciudad escrituraria: su carácter elitista, minoritario y reservado para unos cuantos que, en este caso, participan del engaño; y su aceptación como vía legitimadora del progreso, la estabilidad social y la civilización, todo ello requerido por este régimen dictatorial, pero como suele ocurrir con los textos de Serna, susceptible de ser pensado para otras realidades.

Finalmente, para completar el relato y la crítica a la protagonista, el texto concluye - por supuesto- con Amélie ungida como tesoro viviente y con la publicación de su Alto vacio, después de borrar la única línea escrita de su trabajo (Serna 2004: 61). Doble moral o vínculos entre campo cultural y poder de los que es difícil desprenderse, ambas son lecturas sugeridas. Después de todo, no hay mucha diferencia desde el inicio del relato entre esos tesoros vivientes y Amélie, salvo los privilegios económicos y de reconocimiento que gozan ellos y que ella anhela.

En la línea de la crítica al autismo literario característico de un proyecto creador que ha olvidado su función comunicativa - "esa oscura raíz de lo inexpresable"-, se inscribe el último cuento a comentar: "La fuga de Tadeo", incluido en el mismo libro. Su temática, para estas alturas del trabajo, no será ya novedosa. A través de la ironía característica de su narrativa, Serna relata la vida y méritos literarios de un escritor ensimismado en su propia obra. La voz narrativa la ubica, 
en esta ocasión, en un gran amigo y admirador del escritor, quien ha desaparecido misteriosamente, propiciando múltiples interpretaciones sobre su muerte. El recorrido narrativo contiene, además, varias referencias a trabajos críticos inventados, al estilo de los textos borgeanos (Serna 2004: 139-140).

De los cuatro cuentos seleccionados para este trabajo, "La fuga de Tadeo" es el único ubicado ficcionalmente en México. Elemento significativo si se considera la similitud de sus planteamientos con la crítica al campo literario mexicano desarrollada por Serna en ensayos publicados el mismo año de la aparición del cuento. En ellos, principalmente en el texto titulado "Hijos de papel" de noviembre de 2001, Serna arremete contra la figura de Mallarmé, emblemática para hablar de una literatura que aspira a una dimensión más allá del mundo tangible, una escritura del vacío.

La imagen que Serna pinta de Mallarmé es despiadada, al concentrar en ella todo su malestar por una literatura que considera estéril (2001: 70). Por esta marcada desautorización, me referiré aquí al Mallarmé que configura Serna en su ensayo, sin sumarme a la descalificación de este autor. Para lograr la desacralización de esta figura, Serna selecciona algunas de las anécdotas menos memorables del escritor francés y esas mismas las traslada al personaje de su cuento. Así, en una clara alusión al Mallarmé de Serna, Tadeo declara: "La literatura nace cuando el hombre descubre que en el mundo real solo hay un insoportable olor a cocina'" (Serna 2004: 139). Paralelamente, en el ensayo puede leerse:

Poeta del vacío, Mallarmé rindió culto a la esterilidad, al grado de considerarla una escala hacia la perfección, y en su tentativa por apresar la nada encerró a la poesía francesa en un callejón sin salida del que no ha logrado salir. En la vida cotidiana solo encontraba "un insoportable olor a cocina" (2001: 70).

Coincidente con esta perspectiva, Tadeo es un escritor que busca alejarse del vulgo y considera que la gran literatura no puede ser comprendida por todos. Su ensimismamiento lo conduce al desprecio por los otros y a un aislamiento extremo, donde al final ni siquiera es capaz de cubrir sus necesidades básicas de alimentación o higiene. Como senala el biógrafo, para Tadeo su obra es lo único que importa, después de todo, como cuestiona el narrador y biógrafo: “ ¿Acaso la literatura no 
ha estado siempre reñida con el sentido común?” (2004: 146). Al grado que, como el Mallarmé de Serna, Tadeo no se conmueve siquiera ante el nacimiento de su hijo, y afirma: "Para mí los productos imaginarios son más importantes que las obras de carne" (145).

En este sentido, la mención al movimiento logocentrista que funda en su juventud para liberar a la literatura de "su anquilosada función comunicativa" (141), así como la atribución a Tadeo de una supuesta tendencia a la masturbación (142), aun a través de la enunciación laudatoria de su amigo, forman parte esencial de la ironía de su descripción. La crítica de Serna juega aquí con el supuesto elogio y la sátira de un extremo del aislamiento de la literatura respecto a una posible función social. La interpretación del biógrafo sobre la desaparición del autor corresponde a este extremo satírico. Para él, el hilillo de sangre que se encontró en el escritorio del maestro representa el "último vestigio de su cuerpo transustanciado", ese abandono y sacrificio que realizó a favor de su obra. Por supuesto, como afirmé antes, se trata de una sátira. Además, el biógrafo se atreve a asumir al final una voz de autoridad al explicar que no cualquiera puede entender esta entrega, "solo algunos espíritus selectos podemos comprender el sacrificio de Tadeo” (151).

\section{Algunas líneas finales}

Desde estos apuntes puede señalarse también la importancia de otras obras de Serna para revisar las formas y temáticas críticas aquí exploradas. Entre ellas, cabe aludir a la novela policiaca o negra — discusión que no compete a estas páginas- El miedo a los animales y los libros de ensayos Las caricaturas me hacen llorar (1996) y Giros negros (2008). Como mencioné al inicio de este trabajo, la crítica cultural de Serna no cede a la condescendencia en estos textos. El manejo irónico y el carácter satírico de su prosa exige al lector reformular sus propias preguntas sobre el ámbito cultural al que pertenece. Además, en estos cuentos se muestra cómo Serna no se limita a un solo espacio geográfico o agente del campo intelectual. Su puesta en escena de los absurdos del reconocimiento público, el juego de las apariencias y las corrupciones del poder abarca diversos espacios, instituciones y actores. Su literatura adquiere así la cualidad de constituirse en espacio del pensamiento, en apuesta reflexiva desde procedimientos de ficcionalización que logran 
dar mayor amplitud y alcance a su propuesta que la mera indicación no ficcional de los vicios de nuestro campo.

Sobre este punto, Even Zohar afirmará que la literatura no funciona simplemente "como un instrumento 'estético' o una diversión para los privilegiados. Se trata, al contrario, de una institución social muy poderosa e importante, uno de los instrumentos más básicos de la mayoría de las sociedades humanas, para ordenar y manejar su repertorio de organización de vida, es decir, su cultura" (1999a: 33). Considero que la narrativa de Serna responde a este enfoque. La literatura ya no es vista solamente como la construcción de un espacio textual, sino como un sistema complejo de interacciones, un espacio que busca ser esencialmente dialogante. Algo que no ocurre tan regularmente como podría pensarse.

\section{Bibliografía}

Bajtín, Mijaíl. La cultura popular en la Edad Media y en el Renacimiento. El contexto de Francois Rabelais. Trads. Julio Forcat y César Conroy. Madrid: Alianza, 1998 (Colección Ensayo).

Bourdieu, Pierre. "Campo intelectual y proyecto creador", en Nara Araújo y Teresa Delgado, coords. Textos de teoría y crítica literarias (Del formalismo a los estudios postcoloniales). México: Universidad de La Habana / Universidad Autónoma Metropolitana-Iztapalapa, 2003: 241-285.

Bourdieu, Pierre. Las reglas del arte. Barcelona: Anagrama, 1995.

Bravo, Víctor. Figuraciones del poder y la ironía. Caracas: Monte Ávila / Universidad de los Andes, 1997.

Cluff, Russell M. et al. Cuento mexicano moderno. México: Universidad Nacional Autónoma de México / Universidad Veracruzana / Aldus, 2000.

Domínguez Michael, Christopher. Antología de la narrativa mexicana del siglo XX, vol. II. 2a . ed. México: Fondo de Cultura Económica, 1996.

Even-Zohar, Itamar. "La literatura como bienes y como herramientas", en Darío Villanueva, Antonio Monegal y Enric Bou, coords. Sin fronteras: ensayos de literatura comparada en homenaje a Claudio Guillén. Madrid: Castalia, 1999a: 27-36.

Even-Zohar, Itamar. "Factores y dependencias en la cultura. Una revisión de la Teoría de los Polisistemas", en Monserrat Iglesias Santos, comp. Teoría de los polisistemas. Madrid: Arco Libros, 1999b: 23-52.

Fouchult, Michel. "¿Qué es un autor?”, en Entre filosofía y literatura. Trad. y pról. de Miguel Morey. Barcelona: Paidós, 1999: 329-360 (Obras esenciales, I). 
Hutcheon, Linda. "Ironía, sátira, parodia”, en Laura Cázares, Ana Rosa Domenella et al. De la ironía a lo grotesco (en algunos textos literarios hispanoamericanos). México: Universidad Autónoma Metropolitana-Iztapalapa, 1992: 173-193.

JEANNET, Frédéric-Yves. "De puntos suspensivos y otras minucias: entrevista con Enrique Serna”, en Temas y Variaciones de Literatura, núm. 6 (México, 1991).

José Agustín. Tragicomedia mexicana 3. La vida en México de 1982 a 1994. México: Planeta / Booket, 2007.

Martínez Andrade, Marina. "Novela y parodia en la obra de Enrique Serna”, en Alejandra Herrera, Luz Elena Zamudio y Ramón Alvarado, comps. Tercer Congreso Internacional de Literatura. Propuestas literarias de fin de siglo. México: Universidad Autónoma Metropolitana, 2001: 245-252.

Rama, Ángel. La ciudad letrada. Hanover: Ediciones del Norte, 2002.

Romero Ramos, Héctor y Pablo Santoro Domingo. "Dos caminos en la sociología de la literatura: hacia una definición programática de la literatura española”, en Revista Española de Sociología, núm. 8 (2007): 195-223.

Serna, Enrique. Amores de segunda mano. México: Cal y Arena, 1994.

SERnA, EnRiQue. "Voluntad de estilo", en Letras Libres, núm. 17 (mayo, 2000): 87.

Serna, Enrique. "Hijos de papel”, en Letras Libres, núm. 35 (noviembre, 2001): 70.

SERnA, ENRIQUe. "José de la Colina: la erudición hedonista”, en Letras Libres, núm. 39 (marzo, 2002): 68.

SERna, EnRiQue. El orgasmógrafo. México: Debolsillo, 2004.

Solares, Ignacio. "Enrique Serna: una agridulce perversidad", en Revista de la Universidad de México, nueva época, núm. 36 (febrero, 2007): 92-94.

TARifeño, Leonardo. "Crónicas del mundo al revés. El orgasmógrafo de Enrique Serna”, en Letras Libres, núm. 37 (enero, 2002): 75-76.

Torres Medina, Vicente. "Enrique Serna: sarcasmo y vitriolo", en Esta narrativa mexicana. México: Universidad Autónoma Metropolitana / Eón, 2007: 391-406.

FECHA DE RECEPCión: 18 de enero de 2012

FECHA DE ACEPTACIÓn: 29 de marzo de 2012 